\title{
Design Anthropology e Design Ativismo: investigando métodos situados
}

\section{Design Anthropology and Design Activism: investigating situated methods}

SERPA, Bibiana; Doutoranda; Escola Superior de Desenho Industrial (Esdi/Uerj)

bibianaoserpa@gmail.com

JULIANO, Clara. Graduanda; Escola Superior de Desenho Industrial (Esdi/Uerj)

clarajuliano@gmail.com

ANASTASSAKIS, Zoy. PhD, Professora Adjunta; Escola Superior de Desenho Industrial (Esdi/Uerj)

zoy@esdi.uerj.br

\section{Resumo}

O artigo visa combinar as áreas do Design Anthropology e Design Ativismo com práticas situadas em uma formação popular feminista. Utilizando a pesquisa por meio do design, buscamos contribuir para novas práticas nos processos participativos de design em articulação com contextos sócio-políticos específicos. Apresentamos os principais conceitos do Design Anthropology e Design Ativismo e relacionamos estas teorias e práticas a três experimentações em campo, analisando o uso de dispositivos de conversação em parceria com uma formação popular feminista. A pesquisa fornece insumos para repensar a prática investigativa e a construção de conhecimento em design e propõe uma ação política para a atividade de pesquisa e prática em design.

Palavras Chave: Design Anthropology; design ativismo; dispositivos de conversação; métodos situados.

\begin{abstract}
The article aims to combine the areas of Design Anthropology and Design Activism with practices within a popular feminist course. By research through design, we aim to contribute to new practices in participatory design processes in relation to specific socio-political contexts. We present the main concepts of Design Anthropology and Design Activism and relate these theories and practices to three field experiments, analyzing the use of conversation disposifits in partnership with a popular feminist course. The research provides inputs to rethink the investigative practice and the knowledge-making in design and proposes a political action for research and practice in design.
\end{abstract}

Keywords: Design Anthropology; design activism; conversation disposifits; situated methods. 


\section{Introdução}

O design participativo tem sua origem nos anos 70 na Escandinávia. Neste contexto, projetos vinculados a novas tecnologias foram implementados promovendo a inserção de grupos de usuários e clientes no processo de design, ao invés de apenas consultá-los superficialmente durante e após o desenvolvimento do projeto como era de costume (Lenskjold et al., 2015; Ehn, 2008; Simonsen \& Robertson, 2013). A criação de estratégias para o envolvimento direto daqueles que deveriam trabalhar com e usar as novas tecnologias levou ao desenvolvimento de modelos para lidar com consensos e manejo de conflitos. Essas estratégias levaram também às ferramentas e técnicas que apoiavam o codesign dos produtos e serviços através de modelos, protótipos, cenários e jogos, a fim de estabelecer um regime mais igualitário entre os diversos participantes (Björgvinsson, 2010)

Colocada nesta virada social do design está a reconsideração do que é design, não em termos de seus objetos mas, fundamentalmente, de seus sujeitos. Nestes processos de design, freqüentemente se discute a inclusão de diferentes vozes antes silenciadas, envolvendo-as em uma série de encontros e uso de diversas ferramentas. Hoje, com necessidade de reformular o design participativo devido à complexidade e dinâmica social, econômica e ambiental, alguns identificam a participação como o objetivo do próprio design (Björgvinsson et al., 2010).

Nesse sentido, DiSalvo (2009) propõe que o design, ao invés de partir da identificação de um problema e, como usualmente esperado, abordá-lo trazendo consigo uma solução, pode ter como papel a descoberta e a articulação de questões relevantes. Nesse caso, o design cumpre o papel de tornar as questões tangíveis, materializando-as e articulando-as com pessoas, eventos e coisas das quais fazem parte, sobre as quais têm influência ou que estão de alguma forma a elas conectadas (Lenskjold, 2011), facilitando a formação de públicos (DiSalvo, 2009). Entende-se, então, o design como processo de engajamento entre pessoas e as "coisas de design"(Ehn, 2011 design things no original), que desafia forças dominantes, estabelecendo novas formas de diálogo e, através da identificação de questões e formação de públicos, cria condições para ação e mudança (Björgvinsson et al., 2010).

Neste artigo apresentamos um estudo em andamento que propõe a interseção entre dois campos de atuação em design, Design Anthropology e Design Ativismo, a partir de uma pesquisa por meio do design. Este modelo de pesquisa associa de forma ativa a produção de conhecimento à ação e à prática (Olander, 2014) e entende a projetação de cenários, objetos ou dispositivos como o principal meio de construção de conhecimento na área (Koskinen et al., 2011). Essa prática de pesquisa permite a composição de novas formas de diálogo e compreensão de questões emergentes e urgentes, mas ainda não formuladas de forma concreta - e que, por se manterem intangíveis, permanecem distantes e intocáveis pelo(s) público(s) afetado(s) (DiSalvo, 2009).

A pesquisa e prática dentro dos campos do Design Anthropology e do Design Ativismo encontram suas temáticas, seus pontos de interesse e desafios em questões políticas e sociais emergentes (Brandt et al., 2011; Markussen, 2013), investigando possibilidades de se trabalhar por meio do design em um contexto contemporâneo de alta complexidade (Anastassakis \& Szaniecki, 2016).

Com intuito de compreender possibilidades de atuação desta outra forma de fazer design 
no sistema político-social colocado, nos aproximamos dos movimentos sociais, em especial do movimento feminista do Rio de Janeiro. O tema dos movimentos sociais tem lentamente retornado à agenda dos pesquisadores depois de uma efervescência nos anos 70 (Gohn, 2011). Essa relação reaparece com características diferentes das antepassadas, já que áreas sociais e sociais aplicadas vêm pautando o campo teórico, questionando marcos interpretativos das décadas anteriores e postulando novos referenciais em função de mudanças no cenário sociopolítico (Ibid).

O engajamento nesta proposta se deu por articulação de uma pesquisa de doutorado e uma pesquisa de conclusão de graduação sob a mesma orientação. As três mulheres envolvidas nesse percurso reconhecem a importância dos movimentos sociais no diagnóstico sobre a realidade social e enxergam a possibilidade de construção de ações coletivas que agem como resistência nesse contexto. As pesquisas conjugadas possuem interesses distintos e complementares e são pautadas pelo intervencionismo inerente ao Design Anthropology e Design Ativismo, que propõe um envolvimento prático com os sujeitos e os contextos de pesquisa.

Partindo da preocupação com o engajamento e a contextualização político-sociais que são fundamentais às disciplinas de Design Anthropology e Design Ativismo, entendemos e assumimos uma posição não apenas como designers mas também, e principalmente, como sujeitos políticos ativos. Para tratar este entrelaçamento disciplinar, nos questionamos como podemos colaborar com o movimento feminista organizado utilizando os conhecimentos e ferramentas do design de forma situada e, a partir dessa pergunta, propomos uma investigação a partir do uso de dispositivos de conversação (Anastassakis e Szaniecki, 2016) na orientação de encontros de formação popular para um grupo de ativistas do movimento feminista no Rio de Janeiro.

Para tal, buscamos métodos que apóiam a pesquisa e prática em design de forma politicamente engajada, alinhando a nossa pesquisa (i) à transdisciplinaridade desenvolvida no campo do Design Anthropology e (ii) às preocupações sócio-políticas postas pelo Design Ativismo. Trabalhando com uma gama de métodos híbridos, esta investigação busca ainda experimentar e contribuir com as metodologias emergentes neste campo da pesquisa por meio do design (Brandt et al., 2011- tradução nossa), que por sua vez ainda não apresenta um conjunto fixo de práticas (Olander, 2014).

Na primeira parte do artigo discutimos brevemente questões postas pelas duas áreas de prática e pesquisa em design, Design Anthropology e Design Ativismo. Em seguida, conceituamos e apresentamos os dispositivos de conversação e suas particularidades no contexto de uma formação popular com ativistas do movimento feminista. Encaminhamos, a partir disso, a análise dos encontros e experimentos. Por fim, debatemos acerca desta investigação e possíveis desdobramentos da pesquisa ainda em andamento.

\section{Design Ativismo}

Na busca por modelos alternativos de prática em design, o Design Ativismo surge como uma contestação aos processos político-sociais neoliberais, que moldaram a cultura da disciplina ao longo do tempo (Julier, 2013). Não há um arcabouço conceitual estabelecido entre os pesquisadores do tema, conforme afirmam Zajzon et al. (2017), que analisaram diversas conceituações para o termo Design Ativismo utilizando os autores mais proeminentes da área, a saber Markussen (2013), Fuad-Luke (2009), DiSalvo (2010); Thorpe (2008), Julier (2013) e 
Armstrong et al. (2013).

Thorpe (2008) vale-se dos conceitos sociológicos de protesto e resistência para entender que Design Ativismo caracteriza-se pelo (i) uso de métodos não-convencionais que rompem com os sistemas de práticas e estruturas do poder institucional e pela (ii) demarcação pública de questões e ação disruptiva de modo a trazer mudanças a favor de grupos negligenciados ou excluídos. Markussen (2013, p. 40, tradução nossa) concorda com Fuad-Luke (2009) quando considera a definição de Thorpe (2008) insuficiente porque não revela os "elementos centrais para a prática" ou seja, "técnicas, métodos para Design Ativismo". Da mesma forma, salienta que o conceito de Thorpe carece de intenções claras e de distinções para o entendimento de tipos de Design Ativismo. No entanto, no que diz respeito à proposta de disrupção, Markussen (2013) parece aproximar-se do conceito de Fuad-Luke (2009) e de Thorpe (2008), que afirmam ser essa a noção central para o entendimento da área.

Armstrong et al. (2013) compreende o Design Ativismo como uma abordagem possível para o design social, assim como design para inovação social e design socialmente responsável, mas os diferencia ao colocar que Design Ativismo tem um viés político intencional, ao contrário dos dois últimos. Em outra direção, Fuad-Luke (2017) distinguiu Design Ativismo do design social tomando por base a orientação teleológica do primeiro e sua diretriz no uso de consenso e dissenso. Para o autor, o design social opera dentro de uma agenda neoliberal, enquanto o Design Ativismo desafia as estruturas de poder e de relações. Entendemos, então, que enquanto o design social se demonstra reformista, o Design Ativismo seria revolucionário em sua essência.

No mesmo caminho, DiSalvo (2010) diferencia Design para política (Design for politics, no original) e Design Político (Political Design). O primeiro, diz o autor, tem como propósito apoiar e melhorar procedimentos e mecanismos de governança por meio de produtos ou serviços advindos do design. Esses projetos podem ser englobados em design social se tomarmos a premissa de Fuad-Luke (2017), já que usam o design para melhorar um sistema posto, buscando o consenso projetual e político, trabalhando a favor da governança e bem-estar social a partir disso. O Design Político, por sua vez, acontece quando o objeto e os processos do Design Ativismo são usados para criar "espaços de contestação" (tradução nossa) e mais do que isso, permite considerar o design como uma prática para "investigação sobre a condição política" (DiSalvo, 2010, p.5).

Conduzindo uma pesquisa que alia o design ao fazer político, DiSalvo (2010; 2015) estende as fronteiras disciplinares do design para incluir múltiplas práticas relacionadas à construção dos ambientes visuais e materiais, incluindo objetos, interfaces, redes, espaços e eventos. Ao introduzir a ideia do design antagonista (adversarial design, no original) como uma prática que "expressa ou permite uma perspectiva política específica de agonismo", DiSalvo (2015, p. 2) entende que o design pode ser um tipo de produção cultural agonística, que fornece bases para a ideia de democracia como intrinsecamente controversa. Afirmar que o design antagonista faz o trabalho de agonismo e que uma abordagem agonística encoraja a contestação e o dissenso como fundamentais significa que os ambientes projetados podem funcionar para promover o reconhecimento de questões e relações políticas, expressar dissensos e tensões e possibilitar reivindicações e argumentos contestatórios.

A ideia de promoção de dissenso e contestação despertada por DiSalvo no contexto político do design é também uma característica importante no desenvolvimento de projetos de 
Design Anthropology, que se mostra um proponente de interação e diálogo para criar alternativas de forma colaborativa, a partir da diferença, em oposição a uma concordância uniforme e distante da complexidade das questões vivenciadas (Costard, 2017). Acreditamos que a interseção do Design Ativismo com o Design Anthropology pode surgir justamente do entendimento dos processos coletivos para a discussão, para a disputa e a controvérsia, além, é claro, da potencialidade do trabalho com temáticas para inclusão social e política

\section{Design Anthropology}

Design Anthropology é um campo acadêmico que se forma a partir da correspondência entre os campos do design e da antropologia, mesclando noções, ferramentas e metodologias desses campos para criar novas formas de construção de conhecimento, não apenas nos campos de design ou antropologia, mas fazendo emergir um terceiro campo transdisciplinar em que colaboram designers, antropólogos e cidadãos (Anastassakis; Szaniecki, 2016).

A pesquisa em Design Anthropology é inclinada à experimentação, incorporando a essência etnográfica do processo aberto e da atenção ao contexto e suas especificidades, assim como ferramentas e modos de pensar do design, facilitando a articulação de novas possibilidades, hipóteses e ideias (Boff \& Halse, 2014). Gatt e Ingold (2013) sugerem que a antropologia, através de práticas tradicionalmente descritivas, encontra-se fundamentalmente desconectada dos acontecimentos e contextos específicos a que se refere - e, portanto, presa de forma estática ao passado. Em contraste, o design se preocupa tradicionalmente em prescrever de forma imperativa soluções finais e estáveis para um futuro supostamente melhor, trabalhando também de forma desconectada com o presente.

Propõe-se, frente a esse cenário, uma antropologia participativa, em que seja possível transformar o espaço do campo e da etnografia, de um espaço descritivo e estático em um espaço de construção coletiva de um futuro próximo (Olander, 2014), mantendo diálogos em tempo real com as pessoas envolvidas nesse processo. Trabalhando com esse objetivo a partir de métodos transdisciplinares, a pesquisa em Design Anthropology conta com a associação entre a observação participante, a abertura dos processos e a atenção ao contexto e suas especificidades com ferramentas e modos de pensar do design, facilitando a concepção de novas possibilidades, hipóteses e ideias (Boff \& Halse, 2014). Dessa forma, traz também o design de volta ao presente, deslocando o foco tradicional do projeto prescritivo, solucionador de problemas, para questões emergentes no agora.

Nesse sentido, os autores propõem trabalhar essas práticas na forma de correspondência com a vida, em que o design (profissionalizado) se assume como um processo também fluido e improvisatório, capaz de responder às questões emergentes nessa malha, sem a ambição de propor um fim ou uma solução permanente. Pensar o processo de design como fluido não significa, porém, ser simplesmente levado pela corrente. O processo se apresenta como movimento contínuo, mas se propõe, de forma crítica, a apontar e abrir determinados caminhos e não outros, tomando uma posição de inconformidade frente ao cenário atual, em que poderes dominantes mantêm um mundo insustentável de desigualdades e devastação (Gatt; Ingold, 2013).

Entender o processo de design desta forma evidencia o potencial do design como ferramenta para materializar o intangível, com atenção aos processos abertos e imprevisíveis . Para tal, posicionamos dispositivos - objetos, imagens, sistemas e dinâmicas - como facilitadores 
de reflexões e engajamento entre pessoas e as coisas de design (Ehn, 2011), sem propor soluções para uma questão, mas pelo contrário: encontrando formas de estar junto à questão e enxergá-la de novas formas (Olander, 2014; Binder et al., 2011).

Esses dispositivos são catalisadores para a construção de uma linguagem compartilhada entre pessoas diversas envolvidas em um projeto ou questão, vindas de áreas e contextos diversos. Essa linguagem construída de forma colaborativa é usada para acessar, interpretar, visualizar, articular e comunicar (Binder et al., 2011) conhecimento implícito. O uso de objetos como ferramentas de diálogo contradiz o papel de protótipos no processo de design como tradicionalmente compreendido, deslocando seu papel do lugar de rascunho, algo que se refina até chegar em uma versão finalizada, para o lugar central de ferramenta facilitadora de participação (Donovan et al., 2013). Esse deslocamento significa repensar os objetos (ou coisas) no processo de design, transformando protótipos em provótipos (Mogensen, 1991), objetos engajadores e provocadores de debates, abertos a interpretações que vão além do controle do designer, proporcionando uma produção coletiva de significados (Anastassakis \& Szaniecki, 2016).

Alinhado à noção de provótipo, nossa pesquisa explora o conceito de dispositivos de conversação, artefatos e peças gráficas experimentais que facilitam o engajamento e o diálogo em torno de determinada questão. Esses materiais também não devem ser entendidos como protótipos, já que, longe de insinuar uma futura versão refinada e final, sua função primária e central é "mediar conversações e provocar a imaginação" (Anastassakis \& Szaniecki, 2016). O dispositivo é "simultaneamente produzido e quer produzir algo" (Olander, 2014): durante o seu processo colaborativo de construção, as ferramentas usadas provocam debates, fazendo emergir questões e subjetividades, tornadas visíveis através dessas mesmas ferramentas. O resultado desse processo é também por si só provocador de novos debates, carregando consigo a visualização de percepções distintas e não se entendendo como peça final, insinuando futuros desdobramentos.

\section{Articulações entre Design Ativismo e Design Anthropology em práticas situadas}

A participação social em movimentos e ações coletivas gera aprendizagens e saberes. Há um caráter educativo nas práticas que se desenrolam no ato de participar quando há negociações, diálogos ou confrontos. Uma das premissas básicas a respeito dos movimentos sociais é que são fontes de renovação e matrizes geradoras de saberes de caráter político-social (Gohn, 2011). 0 vínculo entre o design e as movimentações sociais como uma força geradora de saberes é uma oportunidade de promover novas práticas no interior do movimento e propor novas formas de ver e fazer design.

A interação do Laboratório de Pesquisa em Design e Antropologia com uma iniciativa organizada do movimento feminista do Rio de Janeiro se deu justamente no contexto de entendimento de novas formas de diálogo e construções possíveis junto a uma formação popular feminista. A partir do exposto, mobilizamos ferramentas do design para expandir momentos de presente (Gatt; Ingold, 2013) ao criar espaços de debate em que, utilizando dispositivos de conversação (Anastassakis, Szaniecki, 2016), provocassem discussões e construção de conhecimento sobre questões de gênero entre as participantes. Em coerência com as teorizações apresentadas, o foco das dinâmicas de troca não foi projetar soluções para essas questões, mas explorar problemas e discussões emergentes entre os grupos envolvidos para melhor 
compreendê-los (Binder et al., 2011), em um esforço de criar públicos (DiSalvo, 2009) e estabelecer condições para ação e mudança (Bjørgvinsson et al., 2010). Nesses encontros, a construção de conhecimento se deu principalmente através da construção coletiva de artefatos, que cumpriu o papel de ferramenta de engajamento (Olander, 2014; Boff \& Halse, 2014; Donovan et al., 2013). Assim, os espaços de diálogo criados durante o projeto não buscavam a resolução de conflitos em busca de consenso, mas, pelo contrário, provocar debates a partir do dissenso, incorporando tensões e discordâncias em favor de uma abordagem mais democrática das questões em pauta (DiSalvo, 2015).

\subsection{Apresentação da formação popular feminista}

Esta formação popular feminista foi idealizada e proposta por uma Instituição informal de educação feminista - Universidade Livre Feminista - e aplicada de forma semi-presencial no Rio de Janeiro pela rede Agora Juntas, da qual uma das pesquisadoras faz parte. A turma composta de 20 mulheres foi selecionada previamente por meio de um questionário online. A seleção contemplou diferentes perfis de mulheres considerando raça, classe, sexualidade, território e idade. Essa heterogeneidade foi muito interessante para as dinâmicas propostas e para todo entendimento do funcionamento dos dispositivos de conversação neste contexto. Os encontros tiveram, em média, a participação de 15 mulheres. É importante enunciar que uma das pesquisadoras em design desempenhou o papel de educadora nesta formação. Essa bivalência de funções influenciou o desenvolvimento dos dispositivos de conversação junto às outras pesquisadoras, já que os interesses específicos de cada sujeito também foram colocados em disputa. Essa análise será desenvolvida mais adiante neste trabalho.

\subsection{Preparação aos encontros}

O desenvolvimento desta em parceria com o curso de formação popular feminista significa trabalhar a investigação teórica do Design Anthropology e do Design Ativismo de forma prática em um ambiente real, fora da universidade e do laboratório, envolvendo partes diversas - educadoras, educandas, pesquisadoras e a própria formação como processo educativo. Trabalhar com pesquisa por meio do design, onde a participação das partes interessadas é ativa, implica em trabalhar de forma transdisciplinar, incorporando interpretações e interesses distintos (Brandt et al., 2011). Uma característica marcante desse formato de pesquisa prática é justamente a porosidade que ela apresenta ao longo de seu desenvolvimento (Binder et al., 2011): isso significa que não jogamos apenas com perspectivas e subjetividades diferentes, mas também que as participantes, designers-pesquisadoras, educadoras e outras partes envolvidas buscam coisas distintas de acordo com seus próprios interesses, influenciando o curso da investigação (Brandt et al., 2011).

Sem perder de vista as demandas educativas formuladas para o curso, que foram estruturadas previamente pela Universidade Livre Feminista, desenvolvemos atividades que fazem uso de dispositivos de conversação para cada um dos três encontros. As dinâmicas propostas não fazem uso de ferramentas prontas, mas são elaboradas de acordo com a particularidade de cada encontro: a investigação metodológica que estrutura nossa pesquisa tem interesse em ferramentas contextuais, situadas em contextos específicos, contando com suas particularidades, questões, públicos e possíveis fatores imprevisíveis que moldam esses encontros (Olander, 2014). O processo de elaboração das dinâmicas e os encontros onde elas acontecem são espaços 
orgânicos que influenciam um ao outro, guiando e alimentando a pesquisa através de reflexões das pesquisadoras e do restante do coletivo (Binder et al., 2011). Estas atividades não buscam estabelecer verdades absolutas ou soluções finais, mas mediar o debate e a coexistência de subjetividades distintas, convergentes ou divergentes, tornando-as tangíveis. É importante reforçar que o resultado dessas atividades não deve ser limitado às peças produzidas como fim em si mesmas - a riqueza se encontra justamente no processo de produção dessas peças, quando as participantes tornam visíveis questões e subjetividades em processos de colaboração, utilizando esse processo como espaço de debate (Ibid).

Apresentamos a seguir os dispositivos de conversação desenvolvidos ao longo da pesquisa e as dinâmicas em que se inserem, situando essas ferramentas segundo as particularidades da formação. A partir disso, destacamos e conceituamos essa série de eventos, articulando-a com reflexões acerca das teorias que são a base dessa investigação

\subsection{Encontro 1: Contando histórias através de ícones}

O primeiro encontro realizado teve como base temática a história do feminismo, sendo proposta pelo curso a apresentação de uma linha do tempo geral e local, incluindo fatos históricos globais e locais. A linha do tempo foi produzida pelas pesquisadoras e pelas educadoras em papel kraft de 3 metros por 1 metro, possibilitando maior visualização dos marcos históricos e mais espaço para interações. O objetivo deste encontro era aproximar as educandas da história do feminismo e, ao mesmo tempo, provocar um compartilhamento de histórias pessoais que relacionassem os marcos da história feminista com a própria história de vida das participantes.

A linha do tempo do feminismo foi apresentada pelas educadoras e depois as participantes foram convidadas a interagir com essa história. Primeiro foram distribuídos adesivos para que cada participante indicasse 4 pontos da linha do tempo que dialogassem com sua trajetória e seu feminismo. Essa atividade foi importante para entendermos visualmente onde o grupo se posicionava diante das distintas pautas feministas, o que era um objetivo educativo do encontro para formulação da identidade do grupo e compartilhamento de experiências pessoais.

Ainda na interação da linha do tempo, foi proposto que as educandas refletissem sobre o momento em que se encontraram com o feminismo. Considerando que não existe uma História única, como série objetiva e estática de fatos, mas sim histórias subjetivas e situadas; e que fatos históricos, locais e pessoais se entrelaçam, realizamos uma interação na qual todas se situaram na linha do tempo a partir dos fatos históricos apresentados e construíram a sua história por entre a História do feminismo, entrelaçando-as e borrando a distinção anteriormente imposta. Assim, convidamos as participantes a compartilhar essas histórias e vivências que, para elas, significaram de alguma forma o momento de alinhamento com a luta feminista, utilizando elementos gráficos para mapear e conferir visibilidade/materialidade a essas histórias sobre a linha do tempo.

A escolha de ícones como essas ferramentas foi inspirada pelo trabalho do coletivo Iconoclasistas (2010) e objetivou provocar a troca de histórias por proporcionar pontos de partida concretos para esses diálogos, além de facilitar o engajamento de pessoas que não possuem intimidade com linguagens gráficas na construção visual das histórias. Nessa dinâmica, o material provoca trocas e cumpre o papel de gatilho para evocar tópicos e histórias antes despercebidas (Iconoclasistas, 2010) - nesse sentido, o material funciona como dispositivo de conversação. 


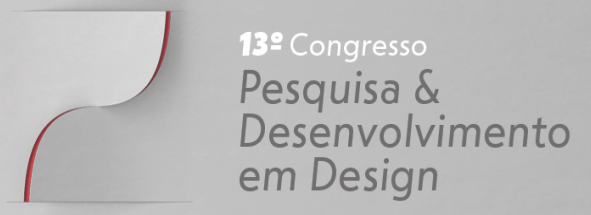

Figura 1 - Atividade do primeiro encontro: intervenções na linha do tempo.

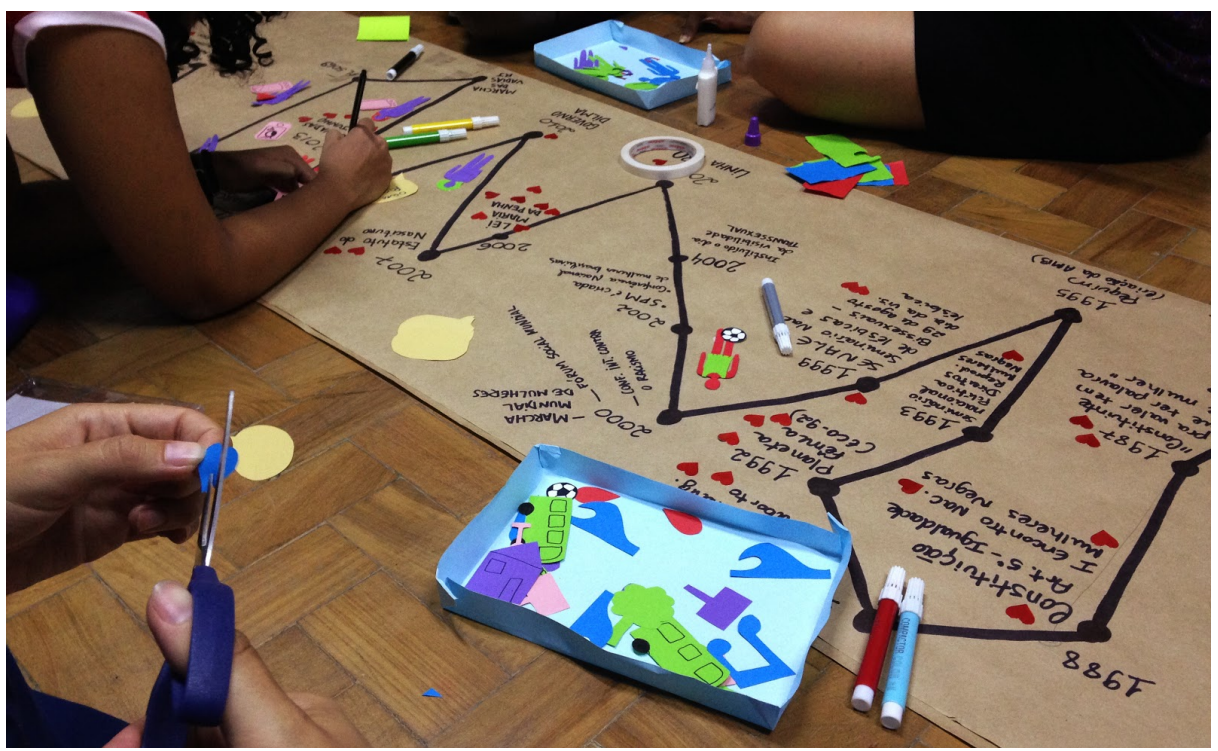

Fonte: as autoras.

Usar a linha do tempo previamente construída pelas educadoras como base para a construção coletiva da peça final pelas participantes foi, por um lado, um limitador, já que prédefiniu os espaços disponíveis para intervenções e trouxe conteúdos fixos. Por outro lado, assim como os ícones, a base agiu também como facilitadora dessa dinâmica, fornecendo um ponto de partida para essas trocas, ao trazer insumos com os quais as participantes poderiam dialogar e associar suas próprias histórias. A peça final criada pelas participantes mapeou histórias e temáticas, situando-as no tempo,e gerando uma nova visualização das diferentes questões que transpassam a vida daquelas pessoas tão diversas.

Já no primeiro encontro dentro da parceria, limitações e disputas de interesses vieram à tona no processo de elaboração e execução das atividades. A atividade aqui descrita, concebida visando atender aos interesses investigativos da pesquisa, foi estruturada de forma a satisfazer também as demandas das educadoras e do curso Por conta das limitações de tempo e da concorrência com as atividades não diretamente relacionadas à pesquisa, considerando o contexto específico do curso e os interesses das educadoras e participantes, a proposta da atividade foi enunciada sem esclarecimentos quanto aos interesses metodológicos da pesquisa. Dessa forma, a atividade causou certa estranheza a princípio, havendo alguma dificuldade na compreensão da proposta, que foge de práticas tradicionais de ensino. No seu decorrer, porém, assim como nos encontros que se seguiram, as participantes se engajaram e se apropriaram das ferramentas oferecidas para construir junto os artefatos propostos. É evidente a importância de que alguns dos interesses em jogo sejam compartilhados por todas as partes e trabalhem no sentido de um objetivo comum - nesse caso, de dialogar e promover espaços de troca acerca de questões de gênero, a partir de uma perspectiva feminista. A temática e demandas do curso foram - e serão consistentemente ao longo dos próximos encontros - elementos fundamentais na construção da dinâmica, estabelecendo um recorte bem definido de trabalho e contextualizando as ferramentas elaboradas. 


\subsection{Encontro 2: Foto elicidação para debate de conteúdo}

O segundo encontro exigia uma discussão em grupo a partir da leitura prévia de dois textos. As participantes foram divididas em dois grupos, cada um responsável pela leitura de um dos textos. O objetivo desse encontro era reconhecer a história do feminismo brasileiro passando pelas diferentes correntes que moldaram o movimento. Cada um dos textos tinha um viés diferente: um apresentava a narrativa pontuada na história por marcos institucionais sob a perspectiva de uma mulher branca acadêmica; o outro narrava de forma mais subjetiva a história feminista sob uma perspectiva da mulher negra, desde a ancestralidade até a contemporaneidade.

A partir da leitura prévia dos textos, as participantes deveriam apresentar o conteúdo lido ao outro grupo, montando cartazes para melhor visualização da narrativa. Não interessa à presente investigação, porém, facilitar visualmente a apresentação do conteúdo de um texto, o foco das pesquisadoras cai sobre o uso de ferramentas visuais e dinâmicas de design para (i) acessar histórias, subjetividades, perspectivas; (ii) construir e experimentar cenários e projeções; (iii) mapear questões, problemas, situações; e (iv) para facilitar debates sobre questões presentes, mas intangíveis.

Buscando atender aos interesses da pesquisa e também da formação como processo educativo, propomos o redirecionamento da atividade de apresentação do conteúdo do texto para dinâmicas de foto-elicitação. O uso dessa ferramenta tem raízes diversas, sendo largamente promovido pelos antropólogos Malcom e John Collier (1986/1996), junto a outros métodos de pesquisa baseados em imagem (Frølunde, 2014). Neste processo, as imagens se apresentam de forma subjetiva, insinuando uma variedade de possíveis significados, o que representa um grande potencial evocativo capaz de trazer à tona uma riqueza surpreendente de informações, sentimentos e memórias (Ibid).

Foram disponibilizadas 60 cartas em formato A6 contendo imagens cotidianas e abstratas que não buscam tratar objetivamente das questões em pauta, mas evocar memórias, reflexões e provocar a imaginação. Essas imagens foram apropriadas pelas participantes para que expressassem experiências e saberes subjetivos a partir de uma linguagem material compartilhada. Em um primeiro momento, foi sugerido que cada grupo escolhesse imagens que remetiam, não necessariamente de forma objetiva, ao conteúdo a ser discutido. A partir disso, elas deveriam organizar esse conjunto de imagens para ilustrar as reflexões individuais e coletivas, associando-as a palavras-chave por elas escolhidas. A escolha de imagens e tópicos abre espaço para um primeiro momento de discussão, engatilhado pela subjetividade das associações, em que se debate sobre o significado dessas cartas em relação à questão em pauta. 


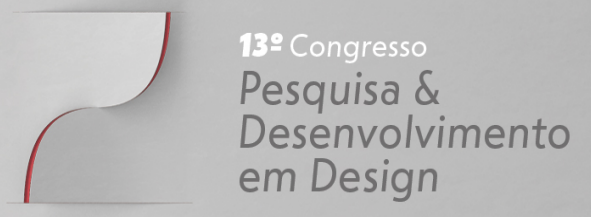

Figura 2 - Atividade do segundo encontro: escolha de imagens.

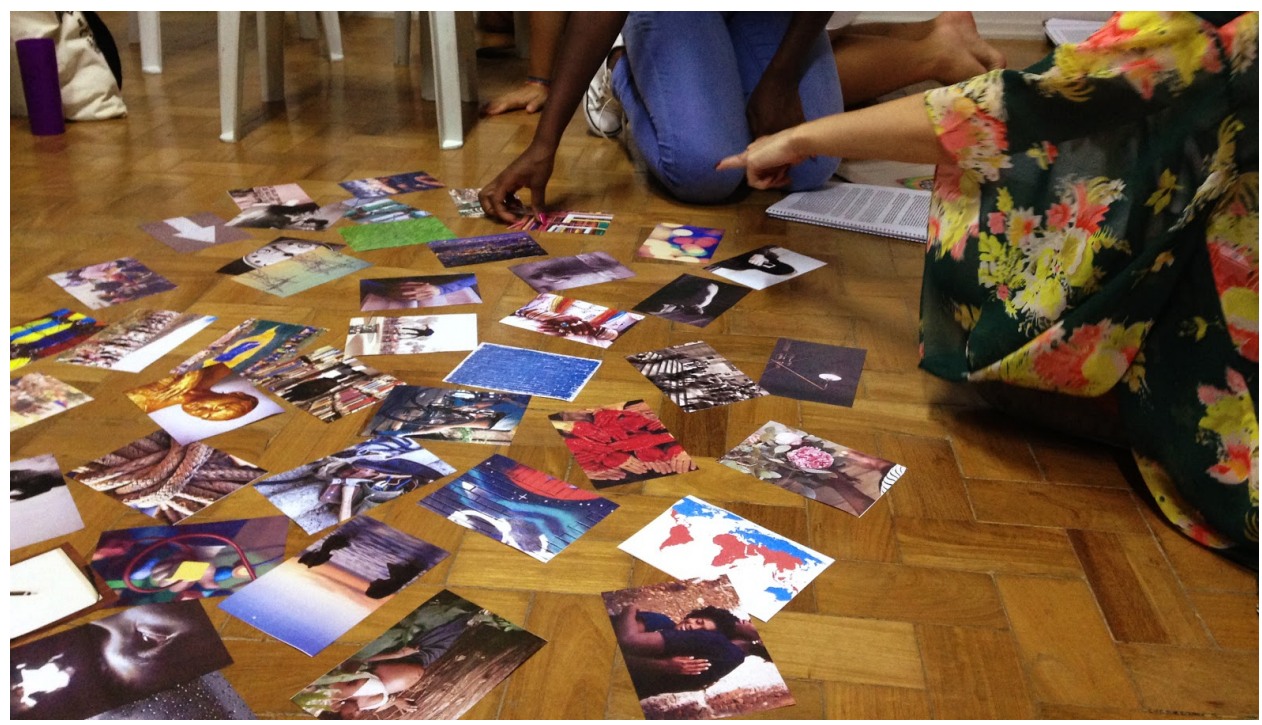

Fonte: as autoras.

Em um segundo momento, os grupos trocaram a seleção de imagens e palavras-chave, de forma que cada grupo recebeu em mãos um conjunto de imagens e palavras mas não tiveram acesso ao conteúdo objetivo que levou a essa seleção. Aqui, o conjunto de imagens e palavraschave tem o potencial de provocar debates não óbvios, fazendo emergir no grupo questões não necessariamente presentes nos textos, mas de alguma forma contida subjetivamente naquele material. As imagens estimularam ideias, histórias, metáforas, associações e memórias. Ao longo do debate, as participantes de cada grupo adicionam novas questões em forma de palavras-chave ou pequenas frases à seleção recebida, montando esse material sobre uma folha de papel de grande formato. A proposta a seguir era que cada grupo apresentasse o material ao grupo que originalmente o selecionou, narrando o conteúdo a partir da sua própria interpretação das imagens e das palavras-chave.

A atividade gerou debates em torno tanto do conteúdo original, proveniente dos textos, como objetivava a programação do curso, mas abriu também novos espaços de discussão, expandindo esse debate para além do que sugeria a proposta original. Provocadas pelas imagens, questões baseadas em vivências das participantes vieram à tona, enriquecendo o diálogo e dando voz a essas mulheres. As questões elicitadas pelas imagens também tornaram evidentes as diferenças e tensões interpessoais que emergiram durante o processo de debate em torno das questões em pauta (Frølunde, 2014). Nesse sentido, as interpretações em torno das imagens são subjetivas e podem entrar em conflito ao longo do processo, de forma a gerar um processo agnóstico (DiSalvo, 2010).

\subsection{Encontro 3: Apropriação de ferramentas de narrativas}

O terceiro encontro tinha como objetivo promover o debate sobre os modos como as opressões de raça, gênero, sexualidade e classe se interseccionam. O programa da formação propunha esse debate a partir da análise de perfis de mulheres e de situações de opressão hipotéticas, sendo estes elaborados pelas educadoras. Para explorar como as ferramentas de 
design poderiam ser usadas na elaboração de atividades que provocassem o engajamento e apropriação dos resultados por parte das participantes (Brandt et al, 2011; Simonsen \& Robertson, 2013), propusemos uma nova dinâmica em formato de jogo, articulando a noção de "dispositivos de conversação" (Anastassakis \& Szaniecki, 2016) à de "coisas" de design (Ehn, 2011 - design things no original).

Foram dispostas sobre o chão cartas coloridas de médio formato, constituindo um tabuleiro em formato de grade. Cada linha do tabuleiro era formada por cartas da mesma cor, previamente vinculadas a diferentes esferas da vida: "vida afetiva", "na rua", "lazer", "no serviço público" e "no trabalho". Paralelamente, foram dispostas cartas contendo perfis de diferentes mulheres. Estes perfis continham informações que definiam raça, classe, sexualidade, identidade de gênero, idade, religião e deficiência. Cada perfil foi identificado com uma foto e nome da personagem.

As participantes foram convidadas a construírem histórias a partir do entrecruzamento do perfil e da esfera de vida. Em pequenos grupos elas deveriam pensar em alguma opressão que determinado perfil de mulher específico (à escolha da participante) poderia sofrer na área de vida relativa ao seu grupo (vida afetiva, rua, lazer, no serviço público e no trabalho) e escrever nas cartas coloridas sem indicar o perfil ao qual a opressão correspondia. As narrativas foram, então, posicionadas no tabuleiro de acordo com as cores (áreas de vida). No decorrer da dinâmica, histórias e vivências das próprias participantes foram evocadas e os materiais apoiaram a elaboração destas histórias baseadas em suas experiências e memórias, fazendo emergir também similaridades e diferenças entre participantes de um mesmo grupo, que também retratavam diferentes perfis entre si.

Em um segundo momento, agora em um grande grupo único, as participantes identificaram quais perfis poderiam viver determinado cenário, debatendo de que forma essas situações se apresentam na vida de diferentes mulheres. A ideia era que uma mesma situação de opressão pudesse ser atribuída a diferentes perfis de mulheres, contribuindo para o entendimento que somos todas permeadas por opressões cotidianas, mas entendendo que essas situações de opressão se materializam de diferentes formas a depender da raça, classe, sexualidade, identificação de gênero, religião, idade ou condição de deficiência.

Para sinalizar os perfis que foram relacionados a cada situação de opressão, foram criados marcadores com os nomes, sendo 15 marcadores para cada perfil. Cada vez que uma situação era relacionada a um perfil, o marcador era colocado sobre a carta-situação. Ao final foi possível visualizar as opressões que são experienciadas por um número maior de perfis e quais perfis estão mais suscetíveis às opressões cotidianas. 


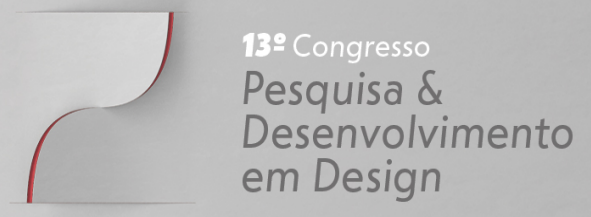

Figura 3 - Atividade do terceiro encontro: narrativas e perfis.

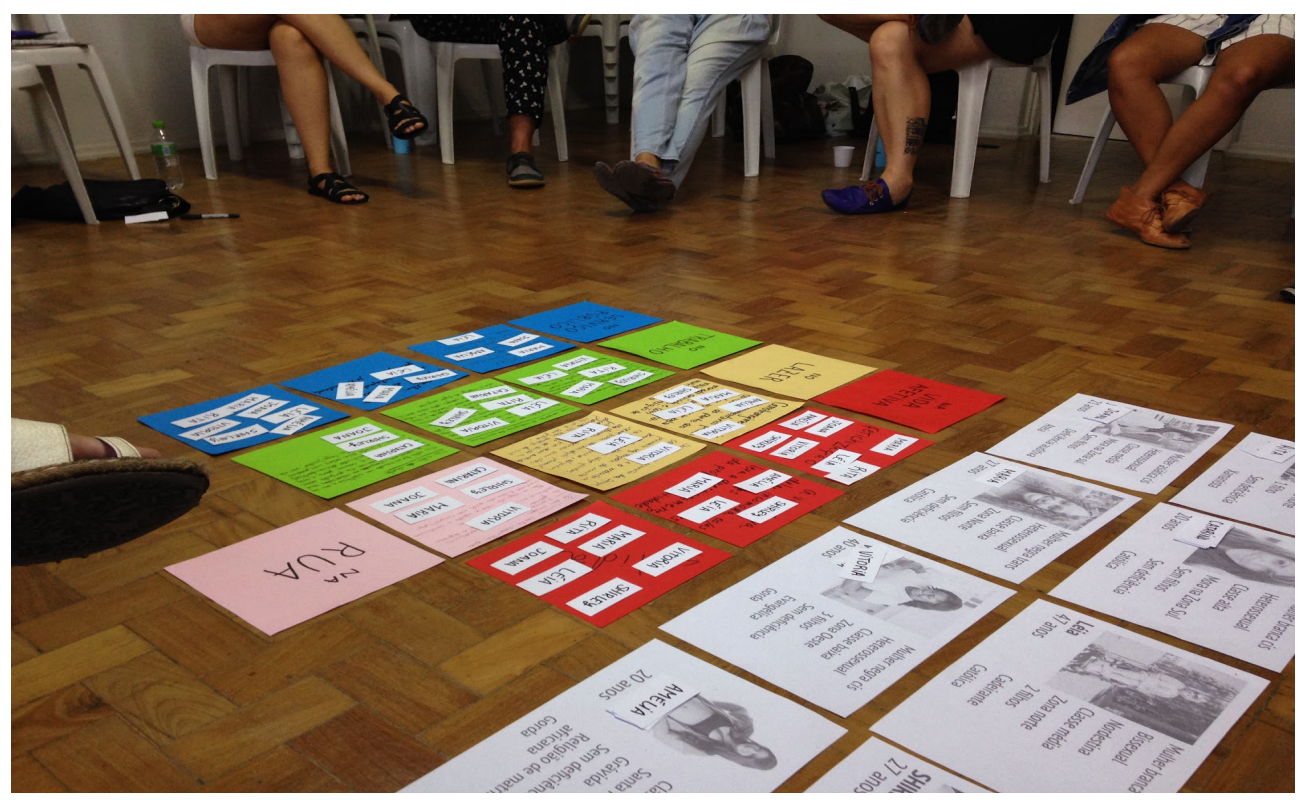

Fonte: as autoras.

A discussão acerca de opressões e perfilamento gerou espaços de contestação (DiSalvo, 2010), o que nos permitiu entender posições afirmativas identitárias e políticas entre as participantes. Nesta atividade, ainda mais do que nas outras, percebemos o lugar central da ferramenta facilitadora de participação (Donovan et al., 2013), principalmente do que se refere à autonomia de fala e gerenciamento de conflitos. Tanto as educadoras quanto as pesquisadoras possuem privilégios político-sociais: são brancas, pertencentes à classe social dominante e não são parte do perfil mais suscetível aos preconceitos diversos. Dessa forma, era difícil direcionarmos a discussão quando participantes negras, por exemplo, reivindicavam situações específicas para sua vivência. No entanto, é interessante entender as atividades são plataformas não necessariamente para resolver conflitos, mas para lidar construtivamente com desentendimentos já postos (Bjögvinsson et al, 2010). Diversas contestações e argumentações foram originadas justamente das diferentes perspectivas postas ao jogar com o tabuleiro, as cartas-situações e os perfis, nos relembrando que os dispositivos são "simultaneamente produzidos e quer produzir algo" (Olander, 2014), que nesse caso foram estopins para discussões pertinentes à formação como processo educacional e à afirmação de identidades entre as participantes.

\section{Considerações finais:}

A partir da questão: "como podemos colaborar com o movimento feminista organizado utilizando os conhecimentos e ferramentas do design?" desenvolvemos uma série de encontros, mediados por dispositivos de conversação (Anastassakis \& Szaniecki, 2016) em parceria com uma organização nacional de educação feminista (Universidade Livre Feminista) e uma coletiva/rede feminista que atua no Rio de Janeiro, Agora Juntas, da qual uma das pesquisadoras faz parte.

Ao longo do processo, as educadoras vinculadas à Agora Juntas participaram da co-criação, ainda que de forma tímida, das dinâmicas e dispositivos de conversação propostos. Os objetivos 
das partes estavam representados e por isso criou-se uma relação horizontal de desejos e demandas, colocando a investigação acadêmica em sua prática a favor da formação e a formação a favor da experimentação proposta. Neste sentido, a disputa de interesses é uma questão que se fez constantemente presente. Como negociar os espaços colaborativos de forma a atender aos múltiplos interesses em jogo? Os interesses metodológicos da pesquisa muitas vezes não são compartilhados, e a malha de intenções, demandas e expectativas pode ser complexa. Nesse contexto, buscávamos experimentar diferentes dispositivos de conversação para explorar processos participativos de pesquisa em design através da prática. Dividindo o espaço desses encontros, as educadoras - entre elas, uma das pesquisadoras, complexificando as relações dentro da parceria - buscavam cumprir com a ementa do curso, desenvolvida por ainda uma terceira parte, idealizadora do curso. As participantes, ainda, visavam concluir a formação, envolvendo-se ao mesmo tempo nos encontros presenciais e nas plataformas virtuais, sendo a segunda alheia às atividades da pesquisa.

Nessa situação, fica evidente a necessidade de que se estabeleçam interesses e objetivos em comum, através dos quais é possível trabalhar essa outra diversidade de demandas (Olander, 2014). Nos encontros da formação é fácil identificar a vontade de debater questões de gênero como esse lugar médio, onde as atividades realizadas cumprem diferentes funções para as diferentes partes ali reunidas: as pesquisadoras puderam experimentar uma diversidade de ferramentas situadas em contextos específicos, acompanhando de perto os processos participativos; as educadoras puderam trabalhar os objetivos propostos pela ementa do curso; as participantes, de forma engajada, tomaram parte na construção dos encontros. Nesse sentido, percebemos a capacidade de trabalho transdisciplinar que define o Design Anthropology. A proposta educacional que envolvia a formação e orientou a experimentação durante os encontros, incorporou a essência etnográfica do processo aberto (que não tem o fim em si mesmo) e propôs atenção ao contexto e suas especificidades, facilitando a articulação de novas possibilidades, hipóteses e ideias (Boff \& Halse, 2014)

É um desafio desse formato de investigação experimental onde a designer se coloca propositivamente dentro de um espaço diverso e real como o curso de formação popular feminista representa. Ao deslocar seu foco do momento de intenção, de onde são idealizadas ferramentas e propostas, para o momento onde essas ferramentas são postas à mesa e apropriadas de formas por vezes imprevisíveis pelas participantes, a designer precisa lidar com o imprevisto e adaptar-se às diferentes situações postas. Enquanto o primeiro momento acontece em um ambiente estéril, controlado pela designer e limitado apenas por demandas prévias, o segundo momento se dá em meio à realidade, onde desejos e subjetividades das diferentes partes envolvidas, assim como possíveis fatores externos, distorcem e transformam as ferramentas e dinâmicas anteriormente propostas, conferindo-lhes sua forma real. O interesse da presente investigação, portanto, se configura não em seguir à risca a proposta inicialmente formulada em cada dinâmica, muito menos obter resultados específicos ou esperados, mas sim munir-se de atenção à complexidade de agentes, interesses e fatores que compõem a malha da pesquisa, tecendo com seus fios, entendendo esses elementos que a tensionam como fundamentais - e, acima de tudo, reais (Ingold, 2015).

Essa realidade é forjada a partir das diferentes identidades evocadas e tem o design como ferramenta engajadora, que desafia forças dominantes, estabelecendo novas formas de diálogo e, 
através da emergência de questões e formação de públicos (DiSalvo, 2010) convidados a enfrentar e propor a mesma realidade, o que cria condições para ação e mudança (Bjorguinsson et al., 2010). Nesse caso, as "coisas" de design (Ehn, 2011) cumprem o papel de tornar as questões tangíveis, materializando-as e articulando-as com pessoas e eventos sobre os quais tem influência ou que estão de alguma forma a ele conectados (Lenskjold, 2011). Da mesma forma, nos questionamos constantemente quais são os limites da participação efetiva nos processos de cocriação (Binder, 2015) e como é possível evitar que as perspectivas das pesquisadoras, embutidas nas ferramentas, condicionem os debates propostos pelas ferramentas.

Ao provocar reflexões sobre assuntos latentes, os encontros não tinham como objetivo prover respostas ou soluções (Brand et al., 2011), mas propuseram questões emergentes que dizem respeito à proposta de disrupção com o modelo neoliberal afrontado pelo Design Ativismo (Markussen, 2013). Relacionamos a experiência relatada ao design que DiSalvo (2010) reconheceu como um tipo de produção cultural agonística, que fornece bases para a ideia de democracia como intrinsecamente controversa, repleta de subjetividades e disputas. É necessário ainda lembrar que essas questões e impasses são inerentes aos processos participativos, de forma que estar junto a eles é também tarefa importante da presente investigação.

A pesquisa, desde o princípio, não teve a intenção de apontar para o futuro, mas sim de expandir momentos de presente (Gatt; Ingold, 2013) para criar espaços de troca e provocar diálogos sobre questões emergentes em determinados contextos. Buscava, assim, contribuir com ferramentas e métodos participativos do design de forma politicamente engajada, para que, a partir do presente, fossem abertos possíveis caminhos para um futuro mais democrático. Acreditamos que os preceitos do Design Anthropology aliados ao Design Ativismo podem contribuir com a reflexão e a ideação das movimentações sociais porque justamente propõem disrupturas e estimulam diálogos agonísticos, intermediados por dispositivos de conversação que "evidenciam e evocam ao invés de argumentar e concluir" (Brandt et al., 2011) e encontram formas de estar junto à questão e enxergá-la de novas formas (Olander, 2014; Binder et al., 2011).

O projeto propõe um processo investigativo aberto e improvisatório, em que busca seguir essas pistas para, nas atividades seguintes, experimentar ainda novas ferramentas e métodos, correspondendo às especificidades de cada contexto. Desta forma, a interação da pesquisa por meio do design com movimentos sociais promove uma outra reflexão à prática de design, que emerge de forma experimental, a fim de explorar possibilidades de combinações entre modelos de produção de conhecimentos distintos (Anastassakis \& Szaniecki 2014). As áreas de Design Anthropology e Design Ativismo são ainda jovens e carecem de teorias e práticas que possam atender suas dimensões de ações e possibilidades. Acreditamos que a relação entre essas duas áreas pode possibilitar avanços na sistematização de ações e na própria definição de seus valores e práticas.

Por fim, percebemos que a interação com os grupos parceiros foi percebido de forma muito positiva, já que o engajamento da turma aumentou após a parceria ser concretizada e a proposta deu dinamismo e maior visualidade aos conteúdos, segundo as educadoras. Reconhecemos, no entanto, a necessidade de explorar novas parcerias se quisermos debater as vinculações dos dispositivos de conversação com processos de aprendizagem. Para além dos conceitos educacionais, há o viés da educação popular e sua particularidade sócio-política diante dos contextos onde é praticada. Nos parece muito interessante, como caminho de pesquisa, 
entender os entrelaçamentos possíveis e as potencialidades do uso de dispositivos de conversação aliados à educação popular na construção de um design político.

\section{Referências}

ANASTASSAKIS, Zoy.; SZANIECKI, Barbara. Conversation Dispositifs: Towards a Transdisciplinary Design Anthropological Approach. In: Design Anthropological Futures. London: Bloomsbury, 2016. ARMSTRONG, L., BAILEY, J., JULIER, G., \& KIMBELL, L.. Social Design Futures: HEI Research and the AHRC. Benford, 2013.

BINDER, Thomas; DE MICHELIS, Giorgio; EHN, Pelle; JACUCCI, Giulio; LINDE, Per; WAGNER, Ina. Design Things. The MIT Press, 2011.

BJORGVINSSON, E. et al. 2010: Participatory design and democratizising innovation. Proceedings of PDC, Sydney, Austrália, 2010.

BRANDT, E.; REDSTRÖM, J.; ERIKSEN, M. A.; BINDER, T. XLAB. The Danish Design School Press, 2011.

COSTARD, M. "Rio Comprido em Nós": do espaço público à construção do público por meio do design. Arcos Design, v. 10, n. 1, 2017

DISALVO, C. Design and the construction of publics. Design Issues: Volume 25, Number 1 Winter 2009.

Design, democracy and agonistic pluralism. Proceedings of the design research society conference. 2010.

Adversarial Design. Cambridge e Londres: The MIT Press, 2015.

DONOVAN, J.; GUNN, W., INGOLD, T. Design and Anthropology. Ashgate Publishing Ltd., 2013.

FUAD-LUKE, A. Design activism: beautiful strangeness for a sustainable world, Routledge, 2009.

. Design Activism's teleological freedoms as a means to transform our habitus. Disponível em: http://agentsofalternatives.com/?p=2539. Acesso em 01 de março de 2018.

HALSE, J; Boff, L. Design interventions as a form of inquiry. Paper presented in the first seminar of the Research Network for Design Anthropology. Aarhus University, 2014.

ICONOCLASISTAS. Manual de Mapeo Colectivo: recursos cartográficos críticos para procesos territoriales de creación colaborativa. Tinta Limón, 2013.

INGOLD, Tim. The Life of Lines. Routledge International, 2015.

FRØLUNDE, L. Reflexive Learning through Visual Methods. In: SIMONSEN, J.; SVABO, C.; STRANDVAD, S. M.; SAMSON, K.; HERTZUM, M.; HANSEN, O. E. Situated Design Methods. Cambridge: The MIT Press, 2014. pp. 161-179.

GATT; INGOLD, T. From Description to Correspondence: Anthropology in Real Time. In: GUNN, W.; OTTO, T.; SMITH, R. C. Design and Anthropology: Theory and Practice. Londres, Nova lorque: Bloomsbury Academic, 2013. pp. 139-158

GUNN, W.; DONOVAN, J. Design Anthropology: An Introduction. In: GUNN, W.; DONOVAN, J. 
(eds). Design and Anthropology. Surrey, Burlington: Ashgate, 2012. pp. 1-16.

GOHN, M. Movimentos sociais na contemporaneidade. Revista Brasileira de Educação v. 16, n. 47 maio-ago, 2011.

JULIER, G.. From Design Culture to Design Activism. Design and Culture, (5)2, 215-236, 2013.

KOSKINEN, Ilpo; ZIMMERMAN, John; BINDER, Thomas; RESTRÖM, Johan; WENSVEEN, Stephan. Design Research Through Practice: from the Lab, Field and Showroom. Morgan Kaufmann, 2011.

MARKUSSEN, T. The Disruptive Aesthetics of Design Activism: Enacting Design between Art and Politics. Design Issues, 29(1), 38-50, 2013.

OLANDER, S. The Network Lab: A proposal for design-anthropological experimental set-ups in cultural work and social research. Tese de doutorado. The Royal Danish Academy of Fine Arts, School of Design. 2014

SIMONSEN, Jasper; ROBERTSON, Toni. Routledge International Handbook of Participatory Design. Routledge, 2013.

SIMONSEN, Jesper; SVABO, Connie; STRANDVAD, Saa Malou; SAMSON, Kristine; HERTZUM, Morten; HANSEN, Ole Erik. Situated Design Methods. The MIT Press, 2014.

SMITH, R. C.; VANGKILDE, K. T.; KJAERSGAARD, M. G.; OTTO, T.; HALSE, J.; BINDER, T. Design Anthropological Futures. Bloomsbury Academic, 2016.

THORPE, A. Design as activism: A conceptual tool. In: Changing the Change, Turin, 2008. Proceedings. Turin, p. 1523-1535, 2008. 